\title{
A Licenciatura em Educomunicação e as novas diretrizes para 0 Ensino Fundamental
}

Ismar de Oliveira Soares

Professor titular do Departamento de Comunicaçoes e Artes da ECA/USP.

Coordenador do Núcleo de Comunicação e Educação (NCE)*.

Membro do Pontifício Conselho para as Comunicações Sociais (Vaticano 2001-2009).

Coordenador do Projeto Mídias na Educação, do MEC, para o Estado de São Paulo.

E-mail: ismarolive@yahoo.com

Resumo: Acaba de ser instalada no Brasil uma nova proposta pedagógica de graduação, com dois centros formadores, um na Universidade de São Paulo e outro na Universidade Federal de Campina Grande-PB, dando início, respectivamente, a uma licenciatura e a um bacharelado em Educomunicação. Os novos programas surgem no momento em que o Conselho Nacional de Educação publica as novas Ensino Fundamental de Nove Anos, abrindo um imenso campo de trabalho para o novo profissional, ao autorizar a escola a compartilhar a tarefa de educar e de cuidar com especialistas de outras áreas, entre as quais a que contempla as relações entre a mídia e a educação. $O$ presente número celebra tais acontecimentos e oferece uma série de artigos que envolvem conceitos como produção comunicativa, arte, ética, recepção, consumo, ensino e censura, uma colaboração para o entendimento do fenômeno da comunicação em suas imbricações com as práticas educativas.

Palavras-chave: Educomunicação, Educomunicador, Diretrizes curriculares, Políticas públicas de educação. Diretrizes Curriculares Nacionais para o

Abstract: It has just been installed in Brazil a new pedagogical proposal for undergraduate education, with two training centers, one at the University of São Paulo and another at the Federal University of Campina Grande, inaugurating, respectively, a major and a bachelor's degree in Educommunication. The new programs have come in a moment in which the National Council of Education published the new National Curriculum Guidelines for Elementary School, opening a huge field of work for new professionals, in authorizing the school to share the task of educating and caring with specialists from other areas, including those which regard to the relationships between media and education. This issue of the journal celebrates such events and offers a series of articles involving concepts such as communicative production, art, ethics, reception, consumption, education and censorship, a collaboration to understand the phenomenon of communication in its relationship with educational practices.

Keywords: Educommunication, Educommunicator, Communication management, Curriculum Guidelines, Public Policy Education.

O ano de 2011 traz aos leitores da revista Comunicação E Educação uma excelente notícia. Finalmente foi instalado, no dia 28 de fevereiro de 2011, na

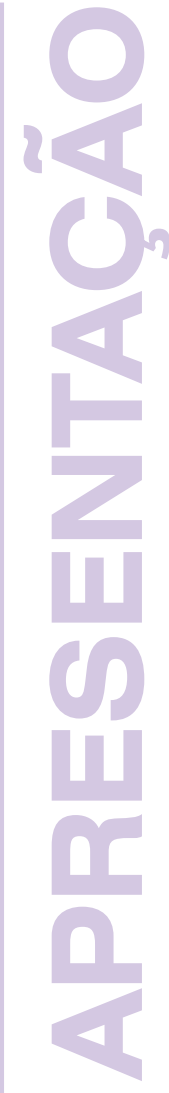

* O NCE localiza-se na Av. Prof. Lúcio Martins Rodrigues, 443 - bloco 9, sala 8 - Cidade Universitária - CEP 0558-900 - São Paulo/SP - Tel.: (11) 3091-4784. E-mail: nce@ edu.usp.br. 
comunicação \& educação • Ano XVI • número 1 • jan/jun 2011

Escola de Comunicações e Artes da Universidade de São Paulo (ECA/USP), um curso de Licenciatura em Educomunicação.

$\mathrm{Na}$ verdade, a ideia de se criar um curso superior destinado a formar especialistas para atender às demandas sociais na área transdisciplinar da comunicação/educação havia sido apresentada no mesmo ano em que nascia, na universidade, a presente revista: 1994. Os docentes e pesquisadores do Departamento de Comunicações e Artes, liderados por Maria Aparecida Baccega, objetivavam, com as duas iniciativas - a revista e o curso -, colaborar para a melhoria da educação, no país, através da atuação de um profissional capaz de entender a natureza singular dos fenômenos que ocorrem e se estabelecem, quando os mundos da comunicação e da educação se tocam, na escola ou fora dela.

Naquele momento, há aproximadamente 17 anos, a direção da ECA não se sentia suficientemente segura para assumir a empreitada. Não estava claramente delineado o papel que um educomunicador poderia exercer na sociedade. Por outro lado, as pesquisas em torno da interface comunicação/educação eram setoriais, permanecendo polarizadas ora em torno da relação entre a mídia e o público infantojuvenil (estudos sobre o impacto da mídia ou sobre os processos de recepção), ora assumindo uma visão instrumentalista, com particular atenção ao emprego dos recursos da informação enquanto suportes ou ferramentas (estudos sobre o uso da mídia nos processos de ensino e aprendizagem). As ações decorrentes eram vistas como restritas ao campo da própria educação, não havendo necessidade de formar - na perspectiva da área da educação - um profissional especialmente voltado ao tema da gestão da comunicação nos espaços formais de ensino. No mesmo período, ganhava força no âmbito da comunicação a perspectiva de que era ao mercado (à mídia e ao mundo corporativo que empregava os comunicadores) e não propriamente à academia que caberia a missão de definir o modo como - e o para quê - os profissionais do setor deveriam ser formados. No caso, as faculdades de comunicação (a ECA/USP, entre elas) não demonstravam qualquer interesse em adentrar numa esfera tida, reconhecidamente, como alheia às suas tradicionais áreas de atividade. Em suma, cada campo - o da comunicação e o da educação - cuidava do que presumivelmente a sociedade lhe havia encomendado, descomprometido com o que ocorria numa pouco notada e, portanto, cinzenta interface.

\section{O QUE MUDOU DE 1994 A ESTA DATA?}

Os leitores da revista Comunicação $\mathcal{E}$ Educação não terão dificuldades em encontrar a resposta: o que mudou foi, de um lado, o enfoque das pesquisas e, de outro, a intensidade com que os resultados das experiências realizadas na inter-relação comunicação/tecnologias da informação/educação incidiam na vida tanto da mídia quanto da educação. A partir de 1999, o que ocorria 
nessa interface passou a ser denominado, na ECA/USP, como Educomunicação. $\mathrm{O}$ conceito passou a definir, essencialmente, os procedimentos inerentes ao entendimento da natureza da relação entre a comunicação e a educação, bem como à gestão da comunicação nos espaços das diferentes modalidades da educação - seja a formal (escolar), seja a não formal (desenvolvida fora da escola), e também como a informal (implementada, por exemplo, pelos meios de comunicação) -, mediante o que o Núcleo de Comunicação e Educação NCE/USP - definiu como áreas de intervenção do novo campo'.

A título de exemplo, observou-se, no período, um aumento considerável da cobertura sobre a educação pela mídia, devido em grande parte ao trabalho de agentes sociais como a Agência de Notícias sobre os Direitos da Infância (www.andi.org.br). As pesquisas da agência sobre o comportamento dos meios impressos acabaram por chamá-los à responsabilidade no sentido de introduzir de forma adequada a educação e os educandos em suas pautas cotidianas. $\mathrm{Na}$ área do audiovisual, constatou-se, igualmente, considerável incremento da produção midiática voltada para temas de interesse da cultura e da educação, especialmente nas emissoras de rádio e de televisão, quer nas comerciais, quer nas educativas - estas melhorando sensivelmente a qualidade de suas produções -, com a contribuição de especialistas com experiências no campo representado pela interface comunicação/educação. Recentemente, a gestora do Canal Futura, jornalista Lúcia Araújo, presente nesta edição na seção Entrevista, comentava, em congresso nacional sobre o tema, que sua emissora dava preferência, em suas contratações, a profissionais com o perfil próximo ao de um educomunicador.

Já no espaço da educação, multiplicaram-se, pelo país - em boa parte através de uma pedagogia de projetos implementada com a assessoria de organizações não governamentais, ou mesmo contando com o apoio de núcleos de extensão das universidades -, ações coordenadas que assumiram os parâmetros educomunicativos como sustentação de projetos de envergadura, que acabaram por converter-se, em alguns casos, em política pública.

Exemplos nacionalmente conhecidos são, em nível federal, a formulação do Programa de Educomunicação Socioambiental do Ministério do Meio Ambiente e a inclusão da educomunicação entre os macrocampos do programa Mais Educação, do MEC, destinado a incentivar um Ensino Médio integral de qualidade. Em nível local, destaca-se o Programa de Educomunicação da prefeitura de São Paulo. Este se caracteriza pelo uso de procedimentos da comunicação para enfrentar os problemas de relacionamento no espaço da escola, mediante a gestão compartilhada de ações comunicativas - incluindo o uso das linguagens radiofônica e digital -, envolvendo, simultaneamente e em igualdade de condições, os professores e os alunos, com profunda repercussão na vida da comunidade educativa. No caso, o projeto Educom.rádio, levado a 455 escolas da rede municipal de ensino, entre 2001 e 2004, tem
1. Os Educomunicadores atuam numa ou em várias destas áreas de atividade: (1) Gestão da comunicação nos espaços educativos; (2) Educação para a Comunicação (media education, media literacy, educación en medios, mídia-educação); (3) Mediação tecnológica nos espaços educativos; (4) Expressão comunicativa na educação; (5) Pedagogia da comunicação; (6) Produção midiática voltada para a educação e (7) Estudos epistemológicos sobre o novo campo. 
2. As orientações do MEC estão em dois documentos que se complementam: o Parecer CNE/ CEB n. 11, de 7 de julho de 2010, de autoria do Conselheiro Cesar Callegari, homologado pelo Ministro da Educação, e a Resolução CNE/CEB n. 7, de 09/12/2010, com a norma oficial, ambos publicados no D.O.U. de 9 dez. 2010.

3. Parecer CNE/CEB $n$. 11, p. 10, de 7 de julho de 2010. Disponível em: $<$ http://www.cesarcallegari.com.br//files/arquivos/1292009455.pdf>. hoje continuidade mediante a aplicação de uma lei municipal que garante qualidade de política pública à aplicação do conceito da educomunicação. As iniciativas referidas contaram e continuam contando com a contribuição de profissionais da educomunicação, em nível de especialização, alguns com título de mestre ou de doutor.

Incentivos legais não têm faltado. O Conselho Nacional de Educação/ Câmara de Educação Básica acaba, por exemplo, de publicar as novas Diretrizes Curriculares Nacionais para o Ensino Fundamental de Nove Anos ${ }^{2}$. Uma leitura cuidadosa do documento permite vislumbrar um imenso campo de trabalho para o educomunicador.

Pelo significado paradigmático da nova proposta governamental, não deixa de ser interessante uma rápida visita ao texto do documento. Observamos, inicialmente, que o artigo $6^{\circ}$ das novas Diretrizes, ao apresentar os fundamentos da nova proposta do MEC para o Ensino Fundamental, inclui a estética em igualdade de condições com a ética e a política. Ao fazê-lo, o texto aproxima o cultivo da sensibilidade ao da racionalidade como meta indispensável da política de ensino. Garante, dessa forma, a essencialidade, na prática educativa, do enriquecimento das formas de expressão e do exercício da criatividade, voltados às diferentes manifestações culturais e à construção de identidades plurais e solidárias.

A partir desta perspectiva, a educomunicação tende a ver-se incluída no documento do MEC, quando este reconhece a importância do universo representado pela comunicação social. O documento diz, nesse sentido, em seu artigo 7ㅇ, que a escola deve valer-se dos recursos midiáticos e, na medida de suas possibilidades, submetê-los aos seus propósitos educativos. E justifica, numa visão crítica:

Há que se considerar que a multiplicação dos meios de comunicação e informação nas sociedades de mercado em que vivemos contribui fortemente para disseminar, entre as crianças, jovens e a população em geral, o excessivo apelo ao consumo e uma visão de mundo fragmentada, que induz à banalização dos acontecimentos e à indiferença quanto aos problemas humanos e sociais ${ }^{3}$.

As Diretrizes propõem, em seguida, metas de natureza expressamente educomunicativas, entre as quais o necessário diálogo entre os membros da comunidade educativa, através de uma gestão democrática e participativa dos procedimentos de gestão.

No que diz respeito à relação com o mundo da mídia, os professores são convidados a colaborar para que os alunos se transformem em consumidores críticos. No caso, espera-se que sejam capazes de compreender o ambiente natural $e$ social em que estão imersos, comportando-se com autonomia. Na verdade, o documento reconhece, em diversos momentos, a importância de a escola levar em conta a sociedade da informação, até mesmo para atualizar sua prática didática: "É preciso que se ofereça aos professores formação adequada para o uso das tecnologias da informação e comunicação e que seja assegurada 
a provisão de recursos midiáticos atualizados e em número suficiente para os alunos".

A grande novidade do documento está, contudo, no campo da gestão, ao reconhecer o aluno como partícipe e corresponsável por sua própria educação, sujeito que é de um direito muito especial: o de expressar-se numa sociedade plural. Reconhecidos como interlocutores válidos, a escola deve contemplá-los como agentes ativos no planejamento e na gestão do próprio plano pedagógico, como estabelece o artigo $21, \S 1^{05}$.

Diante dos desafios que os novos paradigmas colocam para o ensino formal, as Diretrizes autorizam a escola a compartilhar a tarefa de educar e de cuidar com os profissionais da escola e especialistas de outras áreas, externos a ela, o que inclui tanto as famílias quanto outros atores sociais, entre os quais os especialistas na relação entre a mídia e a educação.

A expectativa de uma escola melhor, através de uma gestão educomunicativa, fica refletida na conclusão do parecer da Relatoria, que justificou o texto das Diretrizes:

As experiências das escolas que conseguem reverter o jogo e obter melhorias significativas na qualidade do ensino seguem por caminhos bem variados, mas todas têm em comum um fato: é por meio de um projeto educativo democrático e compartilhado, em que os professores, a direção, os funcionários e a comunidade unem seus esforços e chegam mais perto da escola que desejam ${ }^{6}$.

Este parece ser, na verdade, o grande ponto de confluência entre os propósitos da nova educação prevista em documentos como o que define as novas Diretrizes para o Ensino Fundamental e a proposta pedagógica da Graduação em Educomunicação, com dois centros formadores, no Brasil: a USP, com a licenciatura, e a Universidade Federal de Campina Grande, na Paraíba, com o bacharelado em Educomunicação.

\section{ARTIGOS}

A primeira edição da revista Comunicação $\mathcal{E}$ Educação, em 2011, vem confirmar a decisão editorial de manter a coerência do projeto com o contexto histórico em que está inserida a interface comunicação/educação, o que revitaliza a atualidade da publicação no momento em que o país revê suas diretrizes para a educação, e a universidade passa a oferecer um espaço formador para um novo profissional no campo.

É nesse sentido que o artigo internacional, de autoria de Jamile Dalpiaz, privilegia o tema da Cultura jovem e identidade, tendo como foco as representações do funk carioca em Londres. O texto analisa as representações que envolvem não apenas a cultura jovem e a música popular, mas também questões sociais de classe, raça e gênero que as justificam e lhes dão sentido. Para tanto, o documentário Sou feia, mas tô na moda é tomado como objeto de análise. O
4. Ibid.

5. Quanto especificamente à participação do aluno nesse processo de gestão, o art. 21 afirma que, no projeto político-pedagógico do Ensino Fundamental e nos regimentos escolares, o aluno dever ser considerado "o centro do planejamento curricular". Sobre isso, esclarece o parágrafo único do mesmo artigo: "Como sujeito de direitos, - aluno tomará parte ativa na discussão e implementação das normas que regem as formas de relacionamento na escola, fornecerá indicações relevantes a respeito do que deve ser trabalhado no currículo e será incentivado a participar das organizações estudantis".

6. Parecer CNE/CEB n. 11, de 7 de julho de 2010. Disponível em: <http://www.cesarcallegari.com.br//files/arquivos/1292009455.pdf>. 
texto divide-se em duas partes. Na primeira, trata do significado do funk nas favelas cariocas, explorando as características da cultura jovem, da música e da identidade local. Na segunda, identifica as representações do funk no documentário de acordo com o contexto cinematográfico brasileiro e reflete sobre esta produção a partir da teoria multimodal.

Já os artigos nacionais oferecem subsídios para a abordagem de cinco diferentes tópicos concernentes à relação entre cultura, comunicação e educação. São eles: $\left.1^{\underline{0}}\right) \mathrm{O}$ tema do discurso: Ricardo Henrique Almeida Dias e Maria José P. M. de Almeida tratam do tema da divulgação científica, no artigo Um dispositivo analítico para a investigação da leitura de textos de divulgação científica, propondo um dispositivo para a análise da leitura de textos sobre física nas revistas Ciência Hoje e Pesquisa Fapesp; 2ํㅡ) O tema da docência: Rogério Christofoletti afirma, no artigo Ensino de ética jornalística: pedagogias $e$ metodologias de professores, que - embora onipresente e não obstante os esforços dos docentes para dinamizar as aulas - o ensino de ética jornalística ainda carece consolidar conteúdos e abordagens. O estudo se apoia numa amostragem que inclui os cem cursos brasileiros mais tradicionais na área da comunicação. Garante, por outro lado, que este cenário não é exclusividade do Jornalismo, mas diz respeito às diferentes áreas em que se segmenta o ensino da comunicação no país; 3o) O tema da liberdade da expressão: Maria Cristina Castilho Costa comenta, no artigo $O$ "fundo do poço" $e$ as motivações da censura, o processo de censura prévia de $O$ poço (1950), de Helena Silveira, sob guarda do Arquivo Miroel Silveira da ECA-USP. Informa que o processo censório mostra, por um lado, as tendências de uma época e a resistência do status quo ao que era inovador, transformador, provocativo, desconhecido e inusitado. Descreve como os censores estavam à procura dos sinais de subversão da ordem, enquanto a classe artística em geral se mostrava pronta para resistir. Por outro lado, o artigo demonstra como o processo em estudo revela as trocas e influências entre os meios de comunicação, as linguagens, os autores e os artistas, apresentando imbricações novas e nem sempre devidamente reconhecidas; $4^{\circ}$ ) O tema da recepção: Maria Amélia Paiva Abrão, em A comunicação, a recepção e o consumo enquanto práticas culturais: um novo olhar, analisa a denominada sociedade de consumo, caracterizada por constantes e permanentes mudanças, aceleradas pelo avanço da tecnologia. E, nela, como se dá a relação comunicação/recepção/consumo. Este artigo considera que os aspectos materiais e simbólicos dos bens estão intrinsecamente interligados: todo produto possui um significado que lhe é atribuído socialmente e uma face concreta - o objeto per se stante não possui valor enquanto não for socialmente utilizado. $5^{\circ}$ ) O tema da produção midiática: Eduardo Vicente examina, no artigo Música e disco no Brasil: a trajetória do Grupo Eldorado, o papel representado pelas duas emissoras de rádio (AM e FM), bem como pelo estúdio, gravadora, editora musical e a distribuidora de discos. $\mathrm{O}$ artigo enfatiza, especificamente, as atividades do estúdio, criado em 1971, e da gravadora, criada em 1977. 
A Licenciatura em Educomunicação • Ismar de Oliveira Soares

\section{ARTIGO SOBRE GESTÃO}

A sessão reservada a divulgar trabalhos de conclusão do Curso de Gestão da Comunicação (pós-graduação lato sensu), mantido pelo CCA-ECA/USP, traz, neste número da revista, o trabalho de Ligia Maria Prezia Lemos, no artigo intitulado CETVN - Centro de Estudos de Telenovela: "Fale Conosco!". A Gestão da Comunicação on-line. O texto apresenta um histórico do CETVN - Centro de Estudos de Telenovela da Escola de Comunicações e Artes da Universidade de São Paulo, desde sua criação até o período atual, passando por novembro de 2007, data em que seu site - objeto do estudo - foi reformulado. A pesquisa baseou-se na realização de entrevistas, análise comparativa com alguns sites, observação direta da relação do usuário com o site do CETVN, análise de conteúdo dos dados do sistema Fale Conosco e dos e-mails recebidos, pesquisa de opinião e uma rigorosa revisão bibliográfica. O projeto de gestão da comunicação proposto pela autora visa iniciar as discussões sobre a política, os objetivos e a atuação do site e implementar a sistematização de tarefas, a rotina de melhoria contínua do conteúdo e a gestão dos procedimentos com vistas à participação ativa do CETVN na rede mundial de computadores.

\section{ENTREVISTA}

Com o título Educação além da imagem, a sessão traz a jornalista Lúcia Araújo, gerente-geral do Canal Futura - emissora educativa gerida pela Fundação Roberto Marinho. São abordados no texto os desafios e diferenciais de se administrar uma televisão voltada à educação no Brasil, comentando a maneira pela qual o público vê o tema e falando sobre o perfil do profissional necessário aos novos modelos de comunicação que surgem atualmente no mercado.

\section{CRÍTICA}

João Anzanello Carrascoza apresenta o texto $O$ discurso da ironia $e$ o consumo do grotesco na publicidade. O artigo discute a retórica que sustenta a publicidade feita unicamente para o consumo dos publicitários, analisando anúncios de duas campanhas veiculadas em épocas distintas: uma, de 2005, do Clube de Criação de São Paulo, e, outra, de 2010, da produtora de comerciais Corporação Fantástica. Segundo o autor, os publicitários se valem de diversos recursos retóricos para divulgar produtos e serviços, assim como causas sociais e plataformas políticas. Quando produzem material para divulgar no campo os seus trabalhos, ou seja, quando o target são os seus próprios pares, a ironia se destaca, por vezes na forma do grotesco, como figura retórica central. Fato que denota não só uma escolha, mas revela um habitus profissional (de acordo com Bourdieu). 
comunicação \& educação • Ano XVI • número 1 • jan/jun 2011

\section{DEPOIMENTO}

A folclorista Raquel Trindade, filha do poeta, escritor e ativista negro Solano Trindade, leva em frente o trabalho do pai na preservação e renovação da cultura negra no Brasil - por meio de atividades que envolvem diversas formas de arte, entre elas dança, artes cênicas e música. Neste depoimento, intitulado Além do tema, também professor!, Raquel fala sobre a história de sua família, bem como sobre sua trajetória como artista e ativista, tendo como foco central de sua narrativa o desafio e a importância de se manter viva a cultura negra no Brasil.

\section{EXPERIÊNCIA}

Em O cinema a serviço da educação: a experiência das escolas de ensino básico e secundário no Algarve, Ana Catarina Pereira, jornalista, investigadora do Labcom e doutoranda em Ciências da Comunicação na Universidade da Beira Interior - Covilhã, Portugal, relata o projeto Juventude Cinema Escola, coordenado por Graça Lobo, no Algarve, a região mais ao sul de Portugal Continental. O projeto adquiriu uma notoriedade e seriedade contracorrentes.

\section{POESIA}

Com o objetivo de ilustrar a obra de Orides Fontela, Adilson Citelli e Cristine Vargas apresentam uma pequena seleção de poemas publicados ao longo de sua vida. Apesar de sua difícil personalidade, Orides foi rodeada de grandes admiradores e a intensidade com que viveu seus sentimentos é facilmente reconhecida na poesia que produziu, só que de forma mais contida e depurada, em que é possível entrever um desespero transfigurado e seguro nas imagens que explodem.

\section{INDICAÇÕES VIDEOGRÁFICAS E BIBLIOGRÁFICAS}

Neste número, a videografia indicada por Maria Ignês Carlos Magno é o filme Bicho de Sete Cabeças (2001), de Laís Bodansky e Luiz Bolognesi, e os possíveis desdobramentos que o cinema permite para apreendermos como se dá o processo de criação de um filme. As indicações bibliográficas sobre telenovela e sobre Comunicação e Educação apresentam livros, teses e dissertações sobre as respectivas temáticas.

\section{ATIVIDADES EM SALA DE AULA}

Ruth Ribas Itacarambi propõe projetos pedagógicos a serem desenvolvidos em sala de aula com alunos do Ensino Fundamental e Médio, utilizando artigo publicado neste número. 


\section{PAULINAS EDITORA LANÇA COLEÇÃO SOBRE EDUCOMUNICAÇÃO}

A título de conclusão, assinalamos que a Paulinas Editora lançou, no início de 2011, uma coleção de livros voltados para os temas da interface comunicação/ educação. Os dois primeiros títulos resgatam o esforço sistematizador da equipe de pesquisadores da ECA/USP. Em Educomunicação: o conceito, o profissional, a aplicação, Ismar de Oliveira Soares explicita o conceito, apresentando elementos que se constituem num conjunto de contribuições para a reforma do Ensino Médio. Por seu lado, Adilson Odair Citelli e Maria Cristina Castilho Costa coordenam um conjunto de artigos originalmente publicados por esta revista ao longo de seus 17 anos de atividade. No caso, Educomunicação: construindo uma nova área de conhecimento representa um referencial para a construção epistemológica do novo campo, apresentando sua diversidade e pluralidade. 


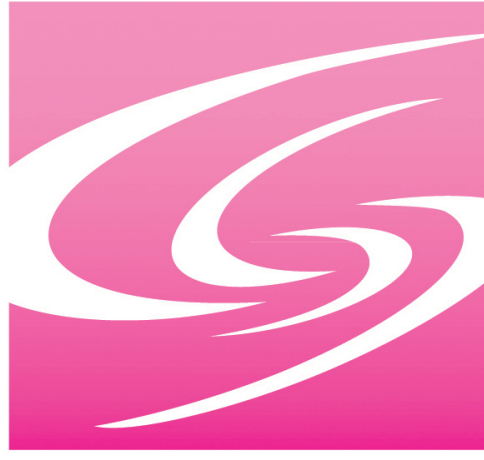

Gestão da

உᄃA EロA பூ口 Comunicação

\section{Curso de Pós-Graduação Lało Sensu O mais experiente e atualizado Curso de Especialização em Comunicação da USP}

\section{Curso de Gestão da Comunicação: Políticas, Educação e Culfura \\ O gestor da comunicação planeja e executa projetos de comunicação em empresas privadas, instituições públicas ou movimentos comunitários nas áreas educacional, empresarial ou artístico-cultural.}

Duração: três semestres

Pré-requisito: formação superior (qualquer área) Seleção: prova escrita, entrevista e plano de estudo

\section{Processo Seletivo Semestral}

1 - semestre: turma com aulas de segunda a quarta-feira

20 semestre: turma com aulas às sextas-feiras e aos sábados.

\section{Objetivos e Diferenciais}

- Capacitação do aluno para eleborar, implantar, avaliar e reestruturar projetos de comunicação/ cultura.

- Integração teórico-prática da área de comunicação com o mercado de trabalho.

- Formação humanística e profissional sólidas, baseada na inter-relação comunicação/cultura/ artes.

- Qualificação do profissional, preparando-o para compreender o mercado emergente, em constante transformação, e agir sobre ele.
Informações $(+5511) 3091-4341$ (+5511) 3091-4867 www.eca.usp.br/gestcom gestcom@usp.br
Endereço

Av. Prof. Lúcio Martins Rodrigues, 443, sl 209

Cidade Universitária São Paulo SP

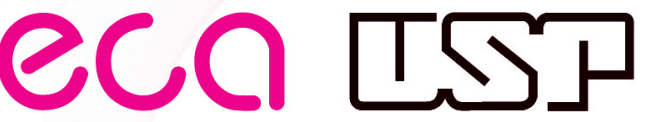

Departamento de Comunicações e Artes 